\title{
A Study to Assess the Knowledge and Attitude of Mothers on Prevention of Diarrhoea Among Infants with Diarrhoea in a Selected Hospital, Bangalore, Karnataka,India
}

\author{
Kogila P., M.Sc \\ Nursing,Associate Professor,Chettinad College of Nursing
}

\begin{abstract}
Acute Diarrhoea is a major cause of morbidity and mortality in infants and young children all over the world, more so in the developing countries, It is equally important to reduce the high rate diarrhoeal deaths because of fluid loss. Its indicating mean scores of knowledge is found better than the attitude scores in all the six aspects. Further the difference in the mean with knowledge and attitude is found significant in the aspects of definition $\left(t=2.28^{*}\right)$, treatment $\left(t=5.03^{*}\right)$, at $p<0.05$ level of significance. In the other four aspect the difference in knowledge and attitude is found to be non-significant. Therefore the research hypothesis was rejected. It is evident that statistical $X^{2}$ test shown the association found significant between Knowledge of mother and the family type $X^{2}$ is $(11.63 *)$, education of the mother $\mathrm{X}^{2}$ is $\left(8.58^{*}\right)$, So the hypothesis $\mathrm{H}_{2}$ stated was accepted.
\end{abstract}

Keywords: Prevention of Diarrhoea, knowledge of motners of infants, attitude

\section{Introduction}

A nation's wealth depends upon its healthy citizen and it applies to all age groups. A healthy adult emerges from a healthy infant. The health of children has historically been of vital importance to all societies, because children are the basic resource for the future of mankind. In a vast biological stretch of early childhood, infancy perhaps is the most critical and vulnerable period. During this period that, there is a high incidence of mortality and morbidity.

The World Health Organization initiated the diarrhoeal diseases control programmes in 1980, approximately four million children died each year due to didehydration, caused by diarrhea. In India at least 1.5 million children under the age of five years die every year owing to acute diarrhea. in the tropical belt , 15 to $40 \%$ of all deaths among children are related to diarrhea

In the view of above facts and investigator experience of working in hospitals with infants found the presence of diarrhoea has certain impact on the infant mortality and morbidity. The main aim to reduce the mortality and morbidity is to prevent the diseases rather then treating and control the infection. Hence, the study was undertaken to assess the knowledge and attitude of mother of infants on prevention of diarrhoea among infants with doarrhoea in selected hospital, Bangalore

\section{Title}

A study to assess the knowledge and attitude of mothers on prevention of diarrhoea among infants with diarrhoea in a selected hospital at Bangalore, Karnataka, India.

\section{Objectives of the Study}

1) To assess the knowledge of mothers on the prevention of diarrhoea among infants with diarrhoea

2) To assess the attitude of mothers on prevention of diarrhoea among infants with diarrhoea

3) To associate the knowledge and attitude of the mothers on prevention of diarrhoea among infants with diarrhoea with selected demographic variables

\section{Operational Definitions}

1) Knowledge

It refers to the level of awareness on prevention of diarrhoea among infants with diarrhoea

2) Attitude

It refers to the expression of feelings and belief of mothers on prevention of diarrhoea among infants with diarrhoea

3) Mothers of Infant

It refers to mothers of infants age between birth to 1year suffering from diarrhoea who are admitted in a selected hospital at Bangalore

4) Prevention Itrefers to reserve for those interventions that occur before the initial onset of diarrhoeal disease

5) Diarrhoea

It refers to the passage of three or more times of watery stools within 24 hours

\section{Materials and Methods}

This study had used non experimental-descriptive design. with quantitative approach and was conducted among the mothers of infants who are attending outpatient pediatric department, who fulfills the given criteria. The sample size was 80 and the sampling technique used was Nonprobability, convenient sampling 


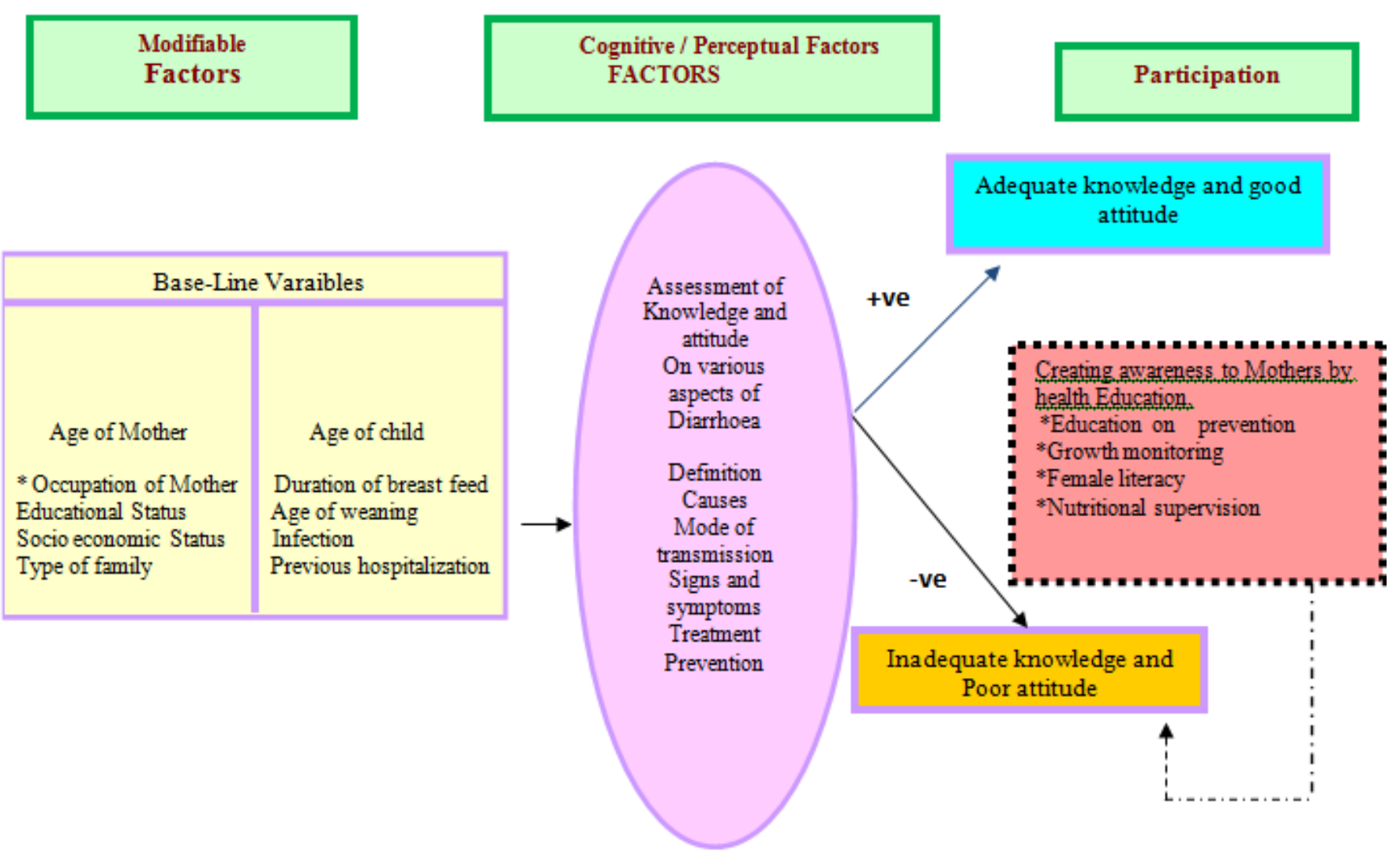

Volume 4 Issue 12, December 2015 


\section{International Journal of Science and Research (IJSR) \\ ISSN (Online): 2319-7064}

Index Copernicus Value (2013): 6.14 | Impact Factor (2014): 5.611

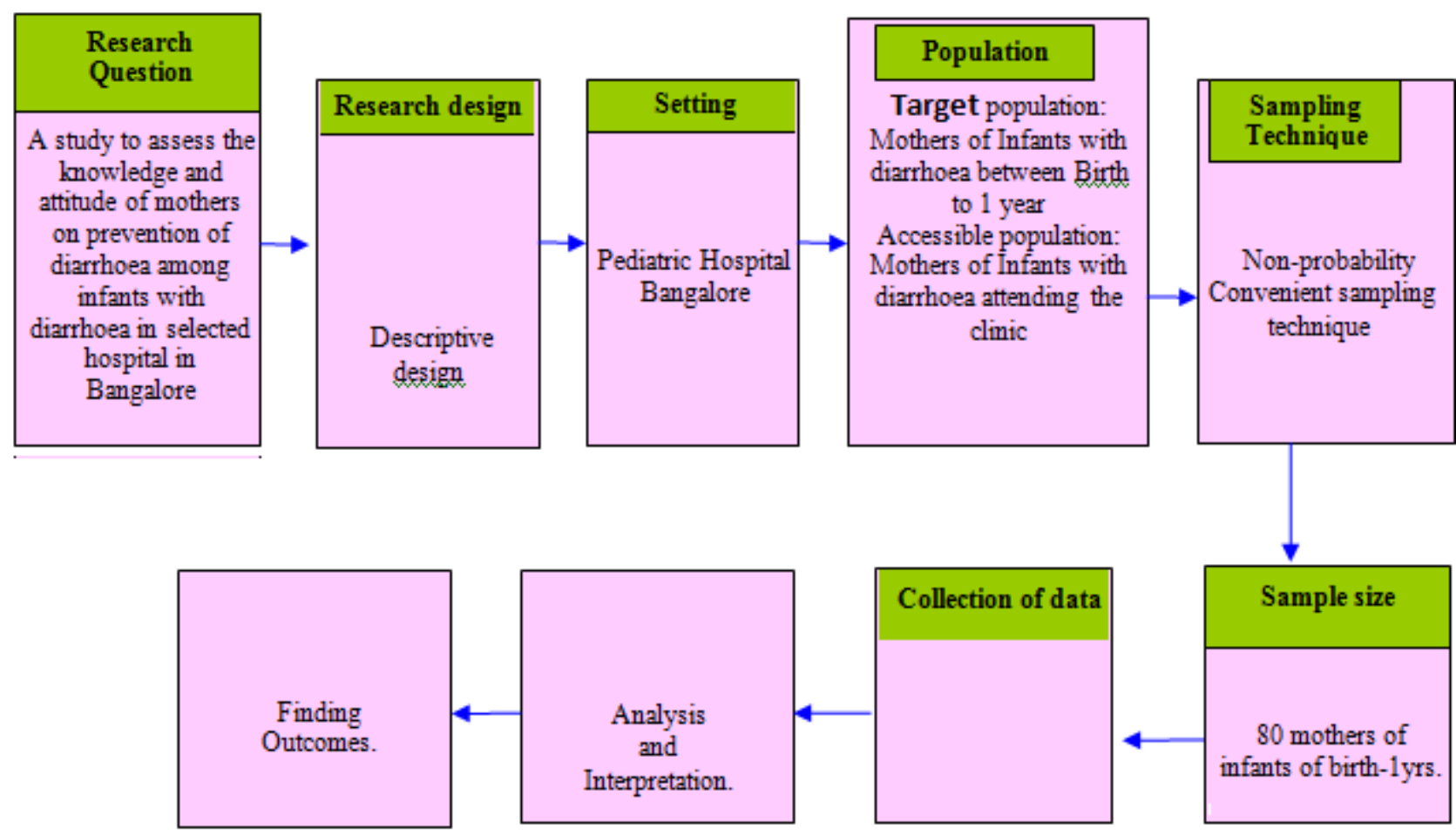

\section{Selection and development of study instruments}

In present study the researcher preparedthe tool consists of three sections.

1) Structured interview schedule to collect the demographic variables of mother and child.

2) Quesstionnaire to assess the knowledge of the mother( 25 in number)

3) Likert scale to assess the attitude of mothers towards prevention of diarrhea (20 in number)

\section{Scoring and interpretation:}

Table 1:

\begin{tabular}{|c|c|c|}
\hline S. No & Level of Knowledge & Score Perentage \\
\hline 1 & Inadequate knowledge & Less than $50 \%$ \\
\hline 2 & Moderate knowledge & $51-75 \%$ \\
\hline 3 & Adequate knowledge & $>75 \%$ \\
\hline
\end{tabular}

\section{Data collection procedure}

In this present study the researcher will assess the knowledge of mother of infants on prevention of Diarrhoea by asking question or conducting interview.

\section{Procedure or Data Collection}

- A prior permission was obtained from the Director of the concerned hospital to assess the knowledge and attitude of mothers of infants with diarrhoea who are attending pediatric OPD, Bangalore

- The investigator introduced herself and the verbal consent from their mothers of infants was obtained. The purpose of the interview and need of questionnaire and likert scale checklist was explained and they were reassured about the confidentiality of the interview.

- The structured interview questioning schedule was carried out on one to one basis for 5 to 10 minutes. By using questionnaire and likert scale check-list each mother's knowledge and attitude were assessed for 30 - 45 minutes.

\section{Plan For Data Analysis}

The data obtained was analyzed by both descriptive and inferential statistics, on the basis of objectives and hypothesis of the study.

- frequencies and percentages. Mean and standard deviation ,Chi-square test ( $\chi^{2}$ test)

\section{Results}

The study results stated that that the aspect wise mean scores of Mothers of infants with diarrhoea. Overall mean in knowledge aspects of mothers found to be $86.52 \%$ with SD as $4.95 \%$ It is seen from the results that the highest mean score noticed in the aspect of definition $98.33 \%$ ( SD 9.1), followed by same percentage for mode of transmission $98.33 \%$ (SD 4.6), and having low percentage for prevention aspects of diarrhoea of $62.50 \%$ (S.D 1.1)

Table 2: Mean, Mean (\%) and SD- knowledge aspects of mothers of Infants with diarrhoea

\begin{tabular}{|c|c|c|c|c|c|}
\hline \multicolumn{6}{|c|}{$\mathrm{N}=80$} \\
\hline \multirow[t]{2}{*}{ No. } & \multirow[t]{2}{*}{$\begin{array}{l}\text { Knowledge } \\
\text { Aspects }\end{array}$} & \multirow[t]{2}{*}{$\begin{array}{l}\text { Max. } \\
\text { Score }\end{array}$} & \multicolumn{3}{|c|}{$\begin{array}{l}\text { Mothers of Infants with } \\
\text { Diarrhoea }\end{array}$} \\
\hline & & & Mean & Mean(\%) & $\begin{array}{l}\text { SD } \\
(\%)\end{array}$ \\
\hline 1. & Definition & 2 & 1.97 & 98.33 & 9.1 \\
\hline 2. & Causes & 5 & 5.80 & 96.67 & 5.1 \\
\hline 3. & $\begin{array}{l}\text { Mode of } \\
\text { Transmission }\end{array}$ & 3 & 1.97 & 98.33 & 4.6 \\
\hline 4. & $\begin{array}{l}\text { Signs and } \\
\text { Symptoms }\end{array}$ & 5 & 1.63 & 81.67 & 4.9 \\
\hline 5. & Treatment & 5 & 1.63 & 81.67 & 4.9 \\
\hline 6. & Prevention & 5 & 1.27 & 62.50 & 1.1 \\
\hline
\end{tabular}




\section{International Journal of Science and Research (IJSR) \\ ISSN (Online): 2319-7064 \\ Index Copernicus Value (2013): 6.14 | Impact Factor (2014): 5.611}

Table 3: Association of Demographic variables of Mothers with overal Aspects of Knowledge, $n=80$

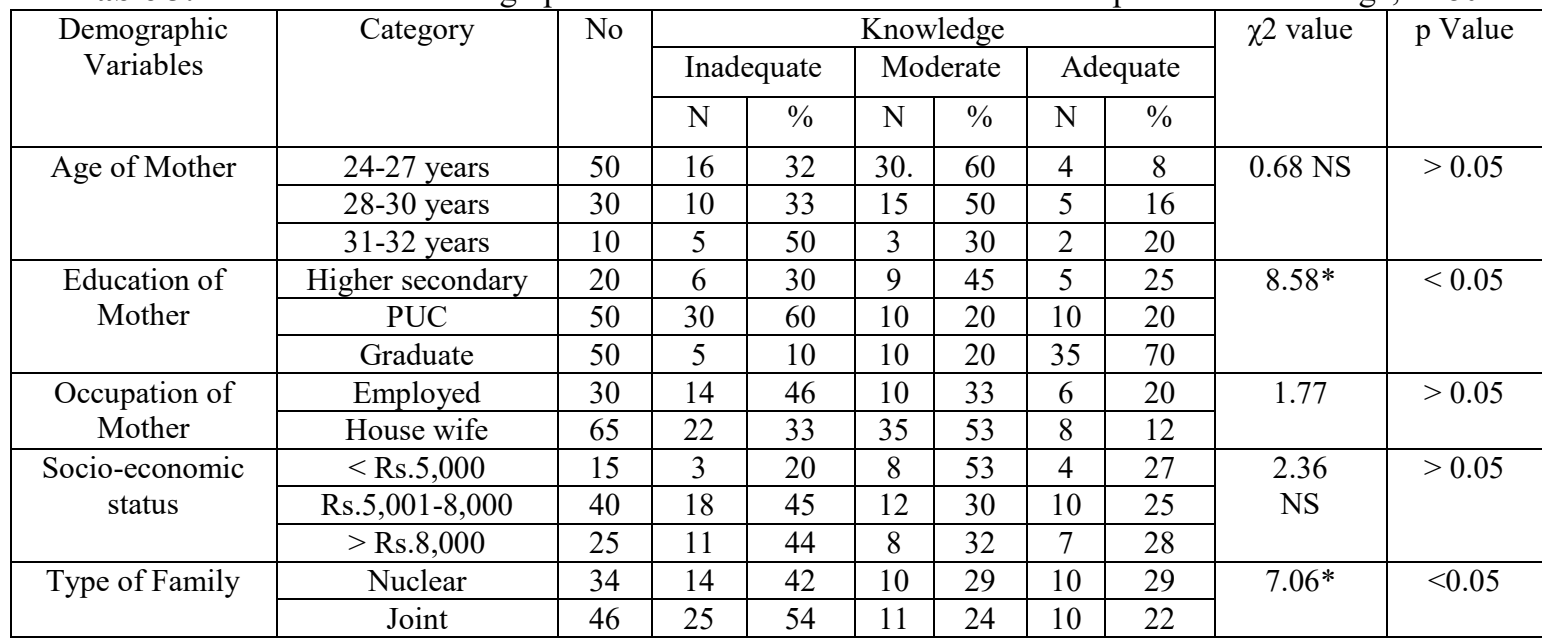

* $(\mathrm{p}<0.05)$ level of Significance, NS : Non-Significant

Table 3: indicates the association of demographic variables of mother with overall knowledge of mothers of infants with diarrhoea. The results showed that mother who were graduate $(70.0 \%)$ and PUC $(20.0 \%)$ had inadequate knowledge

\section{Discussion}

The association of demographic variables of mother with overall knowledge of mothers of infants with diarrhoea. The results showed that mother who were graduate $(70.0 \%)$ and PUC $(20.0 \%)$ had inadequate knowledge.Further, the association between education of mother and knowledge on various aspects of diarrhoea found to be significant $\left(\mathrm{X}^{2}=8.58^{*}\right)$, with other demographic variables under study the association found to be non-significant $(\mathrm{P}>0.05)$..

The association between demographic variables of Infants in relation with the attitude aspects of mother in the Various items of diarrhoea.. It is showed the significant difference between various items of attitude with age, weaning food, child suffered with infection at $\mathrm{p}<0.05$ level of significance.

The demographic variables such as duration of breast fed and previous hospitalization does not showed any significance. With this regard the hypothesis $\mathrm{H}_{2}$ stated was rejected.It is evident from the statistical $\mathrm{X}^{2}$ test that the association found significant between Knowledge of mother and the family type $\mathrm{X}^{2}$ is $\left(11.63^{*}\right)$ and education of the mother $\mathrm{X}^{2}$ is $\left(8.58^{*}\right)$, So the hypothesis $\mathrm{H}_{2}$ stated was accepted.

\section{Conclusion}

Thus the mothers must be aware of this infection, just because this disease causes silent morbidity \& mortality among the Infants.

\section{References}

[1] Dhanajava Sharma et.al., 2014. Prevalence of Acute Respiratory Infection and their determinants in under five children in urban and rural area of Kancheepuram dist., South India. Journals of Pediatric Nursing.
[2] Fa Ujunwa, et.al., 2014. Acute Respiratory Tract Infection in Under Five children. Canadian Nursing Journal.

[3] Kalaiselvi, et.al., 2014. Acute Respiratory Tract Infection among the under five children in India. Indian journals of Nursing Science. 